\title{
REVIEW
}

\section{The cost of alternative models of care for primary care patients attending accident and emergency departments: a systematic review}

\author{
Geraldine M Leydon, Ross Lawrenson, Richard Meakin, Jennifer A Roberts
}

Department of Public Health and Primary Care, Charing Cross and Westminster Medical School, London SW10, UK G M Leydon

R Lawrenson

Department of Primary Care and Population Sciences, Royal Free Hospital School of Medicine, London NW3, UK R Meakin

\section{Health Services} Research Unit, Department of Public Health and Policy, London School of Hygiene and Tropical Medicine, London WC1, UK

J A Roberts

Correspondence to: Geraldine M Leydon, Department of Public Health and Primary Care, Charing Cross and Westminster Medical School, Chelsea and Westminster Hospital, 369 Fulham Road, London SW10 9NH, UK. 13 August 1997
Throughout London several "primary care initiatives" in accident and emergency (A\&E) departments were set up in response to the recommendations of the Tomlinson report ${ }^{1}$ about the management of "inappropriate attenders" at A\&E.

In this paper we describe a systematic review of the literature on the cost-effectiveness of alternative models of $A \& E$ care for the primary care attender and the methodological difficulties involved with undertaking evaluative work in this area.

\section{Economic evaluation}

An economic analysis of the factors associated with the use of $A \& E$ by people with primary care problems involves exploration of the supply and demand for services. On the demand side $A \& E$ has many attractions for people seeking care. Few complaints about "inappropriateness" have come from users of A\&E. Indeed most see their own use as entirely appropriate because of the urgency of the event, the accessibility of the services, the availability of $x$ rays or tests, or the need for reassurance. Even though there are no charges, there are travel and time costs to those attending $A \& E$ and those accompanying them. It is to the supply side, however, that we need to go to understand the arguments about the "inappropriate" use of $A \& E$.

Some of the tensions that arise relate to the nature of the process of care in A\&E. The work of $A \& E$ ranges from minor injuries to major surgical and medical emergencies that occur frequently, but unpredictably, during the day and night. In economic terms primary care and major trauma care are jointly produced but do not dovetail neatly. Staff in A\&E units constantly have to weigh up priorities. They are exposed to the physical reality of the economic concept of "opportunity cost": the time spent dealing with one patient is the lost opportunity to see another patient. The Patients' Charter ${ }^{2}$ has also added to the dilemmas facing busy teams by introducing time limits for initial patient assessment. The playing out of such stresses has to be considered in the context of the financial and resource constraints under which $A \& E$ departments operate.
In response to these pressures and to the questioning of the relevance and acceptability of the category "inappropriate attender," alternative ways of providing care in $\mathrm{A} \& \mathrm{E}$ are being implemented. Detailed evaluation of recent developments in the $A \& E$ department is important to establish how practice has altered. This should include questions relating to the quality of the service, clinical outcomes, patient satisfaction, and economic cost to the NHS and patients. A full economic analysis raises various methodological issues which are considered in the discussion.

This paper is a summary of a systematic review of publications on the subject, commissioned by North Thames Regional Health Authority. ${ }^{3}$ The major objectives of the review were to review studies of the cost-effectiveness of the management of primary care patients in $\mathrm{A} \& \mathrm{E}$; to provide purchasers and providers with evidence of the cost-effectiveness of $A \& E$ models of treatment and care; and to identify where further research is needed.

\section{Methods}

INCLUSION CRITERIA

All published studies (English and nonEnglish) from 1978 to May 1996 were included. Studies had to include patients categorised as primary care, or not "true" accident and emergency patients, a defined intervention, and an identified outcome measure. Although an economic evaluation was originally sought, the search strategy was widened when the paucity of studies with economic evaluations was revealed. Thus studies were included where sufficient detail of resource use was provided to enable cost estimates to be made, or where some comment was made on the economics of the intervention. The patients included in the studies reviewed were those who could be categorised as primary care rather than genuine accident and emergency patients. Primary care patients were taken to be those who could be effectively treated in general practice. Three main types of classification of the primary care attender were used in the studies. Not all fit neatly into these categories, but for the purpose of clarity in evaluating the different interventions, it is 
Table 1 Studies reviewed (reference number)

\begin{tabular}{|c|c|c|}
\hline Author/country & Study title & Sample and length of study \\
\hline Benz \& Shank / USA 1982 (6) & $\begin{array}{l}\text { Alteration of emergency room usage in a family practice residency } \\
\text { program }\end{array}$ & $\begin{array}{l}\text { Age: adults and children Sample size: } 3285 \text { Study period: } \\
\sim 8 \text { months }\end{array}$ \\
\hline Chan et al / USA 1985 (13) & $\begin{array}{l}\text { Referrals from hospital emergency departments to primary care } \\
\text { centres for non-urgent care }\end{array}$ & $\begin{array}{l}\text { Age: adults and children over } 16 \text { Sample size: } 2998 \text { Study } \\
\text { period: } 1 \text { year }\end{array}$ \\
\hline Dale et al / UK 1995 (4) & $\begin{array}{l}\text { Primary care in the A\&E department: prospective identification of } \\
\text { patients }\end{array}$ & $\begin{array}{l}\text { Age: adults and children Sample size: } 2065 \text { primary care } \\
\text { and } 291 \text { A\&E patients Study period: } 1 \text { year prospective }\end{array}$ \\
\hline Dale et al / UK 1996 (11) & $\begin{array}{l}\text { Cost-effectiveness of treating primary care patients in accident and } \\
\text { emergency: a comparison between general practitioners, senior } \\
\text { house officers, and registrars }\end{array}$ & $\begin{array}{l}\text { Age: as above Sample size: as above Study period: as } \\
\text { above }\end{array}$ \\
\hline Derlet et al / USA 1992 (7) & $\begin{array}{l}\text { Triage of patients out of the emergency department: a three year } \\
\text { experience }\end{array}$ & $\begin{array}{l}\text { Age: adults and children above } 15 \text { Sample size: } 21069 \\
\text { over } 3 \text { years Study period: } 3 \text { years }\end{array}$ \\
\hline Hansagi et al / Sweden 1987 (14) & $\begin{array}{l}\text { Trial of a method of reducing inappropriate demands on a } \\
\text { hospital emergency department }\end{array}$ & $\begin{array}{l}\text { Age: adults and children over } 16 \text { Sample size: } 454 \text { primary } \\
\text { care Study period: } 1 \text { month trial }\end{array}$ \\
\hline Kelly / USA 1994 (19) & $\begin{array}{l}\text { Cost containment in the emergency department: shifting the cost } \\
\text { of caring for patients with non emergent conditions from crowded } \\
\text { emergency departments to primary care settings }\end{array}$ & $\begin{array}{l}\text { Age: adults and children Sample size: not stated Study } \\
\text { period: not stated }\end{array}$ \\
\hline Kuens & $\begin{array}{l}\text { "Triaging out" children with minor illnesses from an emergency } \\
\text { department by a triage nurse: where do they go? }\end{array}$ & $\begin{array}{l}\text { Age: children only Sample size: descriptive study of } 100 \\
\text { Study period: sample selected over 3-4 month period }\end{array}$ \\
\hline $\begin{array}{l}\text { MacKoul \& Savageau / USA } \\
1995 \text { (12) }\end{array}$ & $\begin{array}{l}\text { Emergency department utilisation in a large pediatric group } \\
\text { practice }\end{array}$ & $\begin{array}{l}\text { Age: children only Sample size: } 299 \text { emergency charts } \\
\text { Study period: } 3 \text { months }\end{array}$ \\
\hline Meislin et al / USA 1988 (5) & $\begin{array}{l}\text { Fast track: urgent care within a teaching hospital emergency } \\
\text { department: can it work? }\end{array}$ & $\begin{array}{l}\text { Age: adults and children Sample size: } 164 \text { patients Study } \\
\text { period: } 18 \text { days }\end{array}$ \\
\hline $\begin{array}{l}\text { Middleton \& Whitney / USA } \\
1993 \text { (17) }\end{array}$ & Primary care in the emergency room: a collaborative model & $\begin{array}{l}\text { Age: "primary care patients" Sample size: } 133 \text { Study } \\
\text { period: not stated }\end{array}$ \\
\hline $\begin{array}{l}\text { Murphy et al / Republic of Ireland } \\
1996 \text { (9) }\end{array}$ & $\begin{array}{l}\text { Randomised controlled trial of general practitioner versus usual } \\
\text { medical care in an urban accident and emergency department: } \\
\text { process, outcome and comparative cost }\end{array}$ & $\begin{array}{l}\text { Age: adults and children Sample: } 4684 \text { Study period: } 2 \\
\text { months }\end{array}$ \\
\hline O'Shea et al / USA 1984 (20) & $\begin{array}{l}\text { An attempt to influence health care visits of frequent hospital } \\
\text { emergency facility users }\end{array}$ & $\begin{array}{l}\text { Age: primary care patients under } 19 \text { Sample size: } 230 \\
\text { randomly selected from sample of } 445 \text { frequent attenders } \\
\text { Study period: } 1 \text { year following } 2 \text { year selection period }\end{array}$ \\
\hline Selby et al / USA 1996 (16) & $\begin{array}{l}\text { use of the emergency department in a } \\
\text { anisation }\end{array}$ & $\begin{array}{l}\text { Age: adults and children, Sample: } 30276 \text { Study period: } 2 \\
\text { years }\end{array}$ \\
\hline Straus et al / USA 1983 (18) & $\begin{array}{l}\text { Referrals from an emergency room to primary care practices at an } \\
\text { urban hospital }\end{array}$ & $\begin{array}{l}\text { Age: adults and children Sample size: two cohorts, one of } \\
398 \text { and one of } 500 \text { patients Study period: } 3 \text { month trial } \\
\text { referral }\end{array}$ \\
\hline Ward et al / UK 1996 (10) & $\begin{array}{l}\text { Primary care in London: an evaluation of general practitioners } \\
\text { working in an inner city accident and emergency department }\end{array}$ & $\begin{array}{l}\text { Age: adults and children Sample size: } 970 \text { patients triaged } \\
\text { with primary care problems Study period: prospective } \\
\text { survey } 6 \text { weeks }\end{array}$ \\
\hline Anon / USA 1994 (8) & Community health group starts emergency room diversion project & $\begin{array}{l}\text { Age: not stated; Sample size: not stated Sample period: } \\
\text { not stated }\end{array}$ \\
\hline
\end{tabular}

useful to use these models (see the full systematic review for details). ${ }^{3}$

(1) A primary care patient is somebody who could be effectively treated in general practice. For example, they are not likely to require any investigations and are not likely to require hospital admission (for example, Dale et $a l^{4}$ ).

(2) A primary care patient is somebody regarded as "not-urgent," who does not require the attention of an $\mathrm{A} \& \mathrm{E}$ doctor. Some also introduced the length of the presenting condition (Meislin et al, ${ }^{5}$ Benz and Shank ${ }^{6}$ ). For example, a patient with symptoms that have persisted for more than 24 hours without worsening and could wait for 24 hours before being treated (minor abrasions, chronic conditions)..$^{5}$

(3) A primary care patient is somebody who presents with symptoms that are on a preclassified symptom based protocol. ${ }^{78}$

\section{DATA EXTRACTION}

Nine computerised databases were searched for appropriate studies. These were Health, CINAHL, EMBASE, MEDLINE, DHS Database, RCGP, the King's Fund, the Nuffield Institute based at Leeds University, and the NHS Centre for Reviews and Dissemination based at York University.

Organisations with in-house databases conducted searches on our behalf because of public access restrictions. The databases searched by the organisations mostly provided reports of marginal interest. References within articles were obtained and personal contact made with some authors.

\section{DATA SYNTHESIS}

Studies were compared with regard to the patient population sampled and studied; the interventions and related outcomes used; and the methods of costing used and the implications of the results on $A \& E$ resource utilisation.

\section{Results}

Seventeen papers were identified that included a formal economic evaluation or some mention of the cost of the intervention (table 1). Initially too few papers were found, but with the widened search, 14 were considered to be suitable for review and a further three key papers came to light during the course of the study. ${ }^{9-11}$ Of the papers included, three were from the United Kingdom, 12 from the USA, one from the Republic of Ireland, and one from Sweden.

The samples studied and methods used varied. For example, MacKoul and Savageau ${ }^{12}$ used paediatric patients only, Chan et $a l^{13}$ and Hansagi et $a l^{14}$ excluded under 16 s from their sample, and Derlet et al excluded patients under 15 years of age. Study lengths ranged from 18 days to three years. The sample sizes varied considerably, ranging from 100 paediatric patients in Kuensting's three month descriptive study ${ }^{15}$ to Selby's two year copayment study group of 30276 patients. ${ }^{16}$ As indicated above, the definition of what consti- 
Table 2 Study interventions (reference numbers in parentheses)

\begin{tabular}{|c|c|c|c|}
\hline Primary care in $A \mathcal{E} E$ & Primary care diversion & Introduction of a co-payment & Patient education \\
\hline $\begin{array}{l}\text { Dale et al, } 1995(4) \\
\text { Middleton \& Whitney, } 1993 \text { (17) } \\
\text { Meislin et al, } 1988(5) \\
\text { Dale et al, } 1996(11) \\
\text { Ward et al, } 1996(10) \\
\text { Murphy et al, } 1996(9)\end{array}$ & $\begin{array}{l}\text { Anonymous, } 1994(8) \\
\text { Straus et al, 1983 (18) } \\
\text { Kelly, 1994 (19) } \\
\text { Hansagi et al, 1987 (14) } \\
\text { Chan et al, } 1985(13) \\
\text { Kuensting, } 1995(15) \\
\text { Derlet et al, } 1992(7) \\
\text { MacKoul \& Savageau, } 1995 \text { (12) }\end{array}$ & Selby et al, 1996 (16) & $\begin{array}{l}\text { O'Shea et al, } 1984(20) \\
\text { Benz \& Shank, } 1982(6)\end{array}$ \\
\hline
\end{tabular}

tutes a "primary care" patient also varied between studies.

\section{INTERVENTIONS}

A range of interventions and changes in management was identified. These included: triage of patients to primary health care on site at the $A \& E$; triage of patients to other primary health care sites; introduction of co-payments; and patient education.

Table 2 shows the distribution of the studies reviewed among the four broad classifications of intervention. Some of the studies do not fit neatly into these categories, but for the purpose of identifying overall trends in the studies it is useful to classify them in this way.

PRIMARY CARE IN A\&E

Table 2 shows that six of the review studies $^{459-11} 17$ opted for an intervention that provided treatment for patients presenting with primary care type complaints in the $A \& E$ department.

Dale $e t a l^{411}$ acknowledged the need not only to rationalise costs in the context of increasingly sparse resources, but also to provide more "patient appropriate" care. General practitioners were employed on a sessional basis in order to care for patients triaged as primary care. The St James' Hospital study ${ }^{9}$ and the St Mary's Hospital study ${ }^{10}$ also involved referral of patients to general practitioners working within the $\mathrm{A} \& \mathrm{E}$ department.

Middleton and Whitney ${ }^{17}$ staffed a walk in clinic in the emergency room with nurses. Meislin et at implemented a fast track system that could triage patients as non-urgent, to be treated by residents assigned on three to four hour blocks.

PRIMARY CARE DIVERSION STRATEGIES

Eight studies ${ }^{7}$ 12-15 $1819^{19}$ diverted primary care type patients to sites in the community and discouraged the use of $A \& E$ for minor purposes. The main objective underpinning these studies was the reduction of inappropriate or primary care visits to the $A \& E$ department. The most common measure of outcome was the number of $A \& E$ visits following the implementation of the referral system.

Most of the referral programmes provided information and advice on alternative sites of treatment in the community. However, the amount of effort and emphasis placed on this varied between the studies. Some ensured that patients diverted from the $A \& E$ department were seen on the same day or the following day at a primary care site. ${ }^{8}$ Most projects did not routinely do this and consequently many patients may have left the A\&E department without knowing where to seek alternative care. In Derlet's study, ${ }^{7}$ refused patients were triaged to an assistance desk that was open 24 hours a day to inform them of alternative treatment sites. Fifty nine per cent of patients did not use this service.

\section{CO-PAYMENTS}

Selby et $a l^{16}$ considered 30276 patients using an emergency room in a Kaiser HMO (Health Maintenance Organisation) in northern California. Cohorts of patients, those paying and not paying, were compared before and after the introduction of a co-payment charge.

\section{PATIENT EDUCATION}

Most of the studies referred to the importance of patient education. However, only two studies $^{6}{ }^{18}$ formally involved a patient education intervention and a related outcome measure.

The education programme of Benz and Shank ${ }^{6}$ emphasised the importance of telephoning a primary care physician before making an emergency visit. When an "inappropriate" visit did occur the patient would be "immediately" seen by the resident on call and given feedback about appropriate use of the service. A one page memorandum explaining the correct use of the emergency room was available for either physician to give to the patient.

O'Shea et $a l^{20}$ randomly selected $230 \mathrm{pa}-$ tients from a sample of 445 patients identified as frequent $A \& E$ attenders over a two year period. The 230 patients were sent three letters over the first months of 1981 that emphasised the importance of continuity of care.

\section{OUTCOME MEASURES}

Various outcomes were identified. These included: utilisation of the service concerned (A\&E or primary health care clinic or both); waiting times; laboratory and radiographic investigations, treatments and referrals; and patient satisfaction.

\section{Service utilisation}

Most of the studies conducted a comparison of "inappropriate" or primary care attendance to $A \& E$ before and after the intervention to ascertain whether a reduction in service utilisation had been achieved. Three of the eight diversion studies $^{6720}$ and Selby's co-payment scheme ${ }^{16}$ reported a reduction in the number of inappropriate attenders, but referral of patients to primary care services in the community was shown to be largely ineffective in reducing the overall utilisation of $\mathrm{A} \& \mathrm{E}$. 
In O'Shea's study, ${ }^{20}$ a one year follow up after the intervention showed that those receiving a letter decreased their number of annual visits to the emergency room, the primary care units, and subspecialty clinics, but this was also true for the control patients. Benz and Shank's patient education programme ${ }^{6}$ did result in the number of telephone calls before emergency room visits increasing and the percentage of inappropriate visits decreasing. There are, however, obvious dangers with prior approval or managed care schemes-like those in operation in the USA - where patient welfare and medicolegal implications require careful consideration.

Patient education on its own was not shown to produce measurable changes in $A \& E$ attendance by primary care type patients. Changes were either non-existent or negligible. The difficulties of achieving a successful patient education programme are well known. ${ }^{21}$

With the introduction of a co-payment of $\$ 25-\$ 35$, Selby et $a l^{16}$ found that, while there was little change in the numbers classified on discharge as an "emergency," the numbers did decline among the non-urgent patients, leading to an overall fall of $14.6 \%$. Selby et al did not find evidence of excess adverse events in the co-payment groups, but their ability to follow up patients was limited.

Waiting times and patient satisfaction

Meislin's primary care in A\&E intervention ${ }^{5}$ had as its main objective not the reduction of $\mathrm{A} \& \mathrm{E}$ utilisation but the reduction of primary care patient waiting time. The "fast track" did result in a reduction in patient turnaround. The system failed on two occasions when there was a preponderance of acutely ill patients and the residents were diverted to care for them. Satisfaction was measured and compared to the period before the study. Before fast track, the majority of complaints had related to waiting times. Following the study, complaints about waiting times decreased from $79 \%$ to $22 \%$. Dale and Murphy ${ }^{811}$ also showed that patient satisfaction was not adversely affected by the introduction of a primary care initiative in $A \& E$. In fact, Dale et $a l^{11}$ found very high levels of satisfaction - the lower investigation rate of general practitioners did not lead to patient dissatisfaction.

\section{Laboratory and radiographic investigations, treatments, and referrals}

The main outcome measures used for the evaluation of the work in King's College Hospital, ${ }^{4}$ St Mary's Hospital, ${ }^{10}$ and St James' Hospital, Dublin ${ }^{9}$ were diagnosis, laboratory and radiographic investigations, treatments, and referrals. All three studies obtained mutually supportive findings. Dale et al found that patients triaged as primary care and treated by general practitioners at King's College Hospital were less likely to receive investigations, minor surgical procedures, or referrals. ${ }^{11}$ For example, $28 \%$ of A\&E doctor consultations involved radiological tests, compared with $13 \%$ of general practitioner consultations. Ward et al found that at St Mary's A\&E department A\&E doctors investigated $29.6 \%$ of patients (118 of 399) compared with $16 \%(90 / 561)$ of those seen by general practitioners. ${ }^{10}$ Murphy et al, at St James' Hospital, Dublin, ${ }^{9}$ also found that general practitioners undertook fewer investigations, made less hospital referrals, made fewer admissions, but prescribed more often. These findings have direct cost and resource use implications for the provision of primary care in $A \& E$ which are considered in the next section.

\section{ECONOMIC EVALUATION}

Economic evaluations of interventions to treat primary care type patients in $\mathrm{A} \& \mathrm{E}$ are rare. The paucity of economic evaluations made a comparison of costs impossible. However, the studies reviewed were amenable to analysis in terms of the possible implications that such models may have on $A \& E$ resource utilisation.

The cost of providing services is acknowledged by most authors as a crucial factor when considering the implementation of any change in service. Therefore, implicitly one of their objectives was the reduction or at least the stabilisation of costs. Kelly ${ }^{19}$ does provide figures and talks of cost savings ( $\$ 70$ per patient in clinic; $\$ 170$ per patient in emergency department). However, she does not reveal the sources of her figures. Similarly, MacKoul and Savageau ${ }^{12}$ mentions the cost of emergency department use for non-emergency care, but does no more than say that treatment is cheaper in the health centre than in the emergency department ( $\$ 120$ and $\$ 202$ per person, respectively). The paper by Selby et al, ${ }^{16}$ while reporting on the reduction of attendances at the health maintenance organisation, did not discuss any cost savings that might have resulted from the changed pattern of use. Derlet $e t$ al also comment that the $20 \%$ of those triaged away who became better without medical intervention may have important implications in terms of preservation of resources. However, no evaluation of the possible implications on resource utilisation was conducted. In each study the costs involved with the triage process, the referral process, and staff time in making appointments for primary care patients could have been calculated to establish the net saving resulting from the changes in services.

The economic evaluation of the King's initiative was a resource based costing that included administrative costs, consultation costs, diagnostic tests, and treatments. A cost gradient was found among the clinicians providing the service: senior house officers had the highest costs $(£ 19 / £ 58)$, registrars were intermediate $(£ 18 / £ 45)$, and general practitioners had the lowest costs $(£ 12 / £ 32)$. Overlaps in costs would only have occurred in the unlikely event that costs of general practitioner care had been underestimated by $25 \%$ and costs of senior house officers overestimated by $25 \%$. The results were particularly sensitive to costs of admissions. ${ }^{11}$ It should be noted that these costs based on resource use may not reflect the full opportunity costs of the service. 
The randomised controlled trial by Murphy et $a l^{9}$ looked at the numbers of investigations, referrals, prescriptions, types of disposal, and consultation satisfaction. These were used to estimate the comparative costs of providing care for primary care patients in $A \& E$ by general practitioners and the usual $A \& E$ staff. After adjustment for the A\&E case mix, Murphy reported that the marginal cost savings for every 100 representative triage 3 and 4 patients seen by a general practitioner were fIR64 and fIR58 respectively. They conclude that this indicates marginal and total savings of $£$ IR1427 and £IR117 005 respectively for all 2303 patients seen by the general practitioners during the study. The salary costs of the general practitioners during the period were $f I R 21880$. This indicates an overall possible total saving of $£$ IR95 125 . Details of costing methods used in this study were not described.

\section{Discussion}

There are various methodological issues associated with any economic analysis of primary care provision in $\mathrm{A} \& \mathrm{E}$ that require consideration. These include: Epidemiological and clinical problems - the specification of case mix and the large numbers of cases necessary to ascertain differences. Outcome problems -identifying and valuing outcomes. Costing problemsidentifying resources used and apportioning them between activities, and estimating the opportunity costs of their use.

Two other issues are also of major importance: case definition and generalisability of the model. The most crucial methodological issue is what do we mean by "primary care patients." Many A\&E specialists would consider themselves to be providing primary care services to most of their patients, in as much as they are providing first contact care. Others would argue that primary health care patients are those who could and perhaps should be cared for in general practice. The variety of definitions of what forms a primary care attendance raises the question of whether attenders identified in studies are a homogeneous group. This needs to be considered when comparing studies of differing services.

Generalisability also needs to be considered when interpreting the results of any evaluative work. Most of the studies, whichever definition of primary care services in $A \& E$ is used, are geographically defined. The types of treatment that a general practitioner might provide, and therefore what might be considered primary care within $\mathrm{A} \& \mathrm{E}$, is determined by the medical system within which the study is conducted (for example, the differences between the United Kingdom and American health care systems require consideration in the context of this review). The grades of staff considered and the facilities available will differ, as will the available alternatives that might be used by the people seeking these services. Thus a model that is cost-effective in one situation may not be cost-effective in another.

The difficulties of generalisability are especially pertinent to this review because of the very different health care systems the studies derive from (USA, United Kingdom, Sweden). Despite these limits the review is helpful in broadening our knowledge of how differing systems have attempted to provide appropriate care for primary care patients in $A \& E$ and how successful or otherwise each method has been.

We have to question the extent to which interventions like that of Derlet et $a l^{7}$ decrease resource use. It may just be a case of transferring workload-to others in the department and to other providers-rather than reducing it. As Henry ${ }^{22}$ has pointed out, much of the real work has already been done by the time the non-urgent patient leaves the $A \& E$ department. Each patient is interviewed, a history is taken, a physical examination conducted, appropriate action has to be decided upon, and a follow up strategy planned. Economic comparisons should take costs associated with this into consideration.

The economic evaluations that have been undertaken have rarely included the costs to patients and their carers. Some information has been collected by Garcia de Ancòs et al ${ }^{33}$ for the King's study. This includes the time and travel costs to patients and those accompanying them and for those who had to be cared for while the patient was in $\mathrm{A} \& \mathrm{E}$, the time lost from work, and the consequences of this.

The costs in the King's study ${ }^{11}$ did not include overheads or capital charges because it was considered that these costs would not have been saved had the patients not attended A\&E.

In some projects capital has been invested in new schemes and so included in the cost estimates; thus care needs to be taken when comparing these alternatives. However, it does appear that the costs of treating a primary care patient in $\mathrm{A} \& \mathrm{E}$ are low, whatever the mode of delivery. Indeed the unit cost is not appreciably greater than that of consulting a general practitioner in a practice, an important finding given that much of the justifications for changing modes of delivery have been driven by concerns about costs.

An interesting paper that challenges the cost saving hypothesis is that of Williams, ${ }^{24}$ who examined the patients using six community hospitals in Michigan between 1991 and 1993. The patients were classified into urgent, semiurgent, and non-urgent cases. The average and marginal cost of the visits was estimated using regression analysis. These costs were based on hospital charges and physician's fees. It was found that the marginal cost of a non-urgent case was only $\$ 24$ dollars, $55 \%$ of the average costs, and thus potential savings from restrictive interventions were likely to be small.

The effectiveness of alternative interventions in treating primary health care patients in $A \& E$ is difficult to establish. The patients come with a wide range of complaints, have different comorbidity patterns, and will return to very different environments when leaving the $A \& E$ department. Many factors could confound the effects that might arise from the difference in treatment modes. Large numbers of patients would need to be included to distinguish any statistically significant results, and the prob- 
lems of attribution might still persist. Methodological difficulties need to be borne in mind when interpreting the findings of studies in this area.

Given the paucity of economic information in this field, a possible way of proceeding would be to adopt a modelling approach to appraise the feasibility of different options. Dale $e t a l^{25}$ undertook an option appraisal for Bromley Health Authority in an attempt to evaluate different models. The costs of treating a mix of hypothetical patients in a number of alternative models were considered. The lowest costs were associated with the nurse practitioner type units, but the capacity estimates for these were lower. Such models are useful for illustrative purposes, but need to be explored further in more detailed studies that can assess case mix and outcome more extensively.

Finally, no study attempted to place a value on the benefits of alternative provision or the distribution of these costs to the various parties. In addition, not all of the reviewed studies attempted to follow up patients to determine clinical outcome following the primary care intervention. Derlet ${ }^{7} \mathrm{did}_{\text {conduct }}$ some follow up of patients refused care. He identified a total of 14 adverse outcomes, but the follow up methodology was not rigorous enough (for example, the sample size of the follow up group) to enable conclusions to be drawn from this. To fully endorse a revised model of $A \& E$ care the health gain to patients or otherwise would need to be comprehensively assessed.

\section{Conclusions}

Despite the modification of our review inclusion criteria to encompass studies that did not include an economic evaluation, only 17 studies fitted the inclusion criteria. This in itself shows a paucity of relevant work in the field. The studies reviewed differed methodologically and geographically; hence it is not possible to provide categorical evidence to purchasers and providers about the most costeffective model of service provision for primary care attenders in A\&E. In light of this the conclusions listed should be viewed tentatively.

We have shown the following:

- Interventions that divert patients away from $A \& E$ to the community for primary care treatment may be successful in increasing patients utilisation of these services but do not necessarily lead to a reduction of primary care attendances at $A \& E .^{13} 15$

- The provision of specific primary care treatment in A\&E may be associated with greater patient satisfaction. The reduction in waiting times was thought to be a major factor in the increased satisfaction of patients. ${ }^{45911} 15$

- The introduction of a co-payment fee was shown to reduce non-urgent attendances to the A\&E department by $14.6 \%$ among those affected by the scheme. ${ }^{16}$

- Patient education on its own does not appear to produce measurable changes in outcomes. In the majority of studies, change was either negligible or non-existent. ${ }^{60}$
- In spite of the lack of comprehensive costing studies, the small number of options considered, and the methodological issues associated with the studies reviewed, it does appear that the unit costs associated with treating a primary care patient in $\mathrm{A} \& \mathrm{E}$ are not high, and are comparable with treating such a patient in general practice.

- It appears that these costs may be further reduced by the presence of general practitioners in $\mathrm{A} \& \mathrm{E}$, who conduct fewer investigations, ${ }^{4-11}$ but it is not clear how much of this difference is accounted for by experience and how much by the specialist training of general practitioners. A small scale follow up of general practitioners in $A \& E$ patients showed some increase in the use of general practitioners and in subsequent referrals to outpatients in the three months after their hospital visit. ${ }^{11}$

There is a need for the development of standardised methods for the examination of the economic consequences of treating primary care problems. Once developed this would provide a framework that could be used by decision makers to explain the likely cost-effectiveness of planned modifications to the delivery of care. This should address the issues surrounding evaluation of benefits as well as costs.

Important methodological considerations for evaluation studies are:

- Sample size must be sufficient.

- A comprehensive range of costs should be included in the analysis (for example, comprehensive costs to the units providing care and costs to the patient and their families).

- A standardised allocation of costing procedures should be used. ${ }^{26}{ }^{27}$

- Alternative models of service provision need to be scrutinised to ensure that they are addressing comparable health needs.

- Studies should be based on appropriate outcome measures.

- Methods of evaluating such outcomes need to be addressed.

- When considering the economic evaluations of emerging forms of service provision, new services should be monitored until they achieve an efficient level of provision before being evaluated.

The major conclusion to be drawn from this review is the need for more economic evaluation, using standardised methods that can be applied in this innovative and rapidly changing field of service development. The establishment of separate cost centres (that is, separate from $A \& E$ cost centres) for new primary care services in $A \& E$ would enable more accurate identification and apportionment of resources used and thus facilitate evaluative work of this kind.

We thank our colleagues for their advice (particularly Professor George Freeman, Department of Public Health and Primary Care, Charing Cross and Westminster Medical School), and all of those who have participated in our work. We would also like to thank North Thames Regional Health Authority for funding the study.

1 Tomlinson B. Report of the inquiry into London's health service, medical education and research. London: HMSO, 1992. 
2 Department of Health. The Patient's Charter HMSO: London, 1991.

3 Leydon GM, Lawrenson R, Meakin R, Roberts JA. The cost of alternative models of accident and emergency care: a systematic review. A Report to North Thames Regional Health Authority. London: Charing Cross and Westminster Medical School, Department of Public Health and Primary Care, 1996 .

4 Dale J, Green J, Reid F, Glucksman E. Primary care in the accident and emergency department: I. Prospective identification of patients. BMJ 1995;311:423-6.

5 Meislin HW, Coates SA, Cyr J, Valenzuela T. Fast track: urgent care within a teaching hospital emergency department: can it work? Ann Emerg Med 1988;17:453-6.

6 Benz JR, Shank CJ Alteration of emergency room usa in a family practice residency program. J Fam Pract 1982;15: 1135-9.

7 Derlet RW, Nishio DA, Cole LM, Silva J. Triage of patients out of the emergency department: three year experience. Am J Emerg Med 1992;10:195-9.

8 Community health group starts emergency room diversion Community health group starts emergency room diversion
project. Health Care Strategic Management (January) 1994;16-18

9 Murphy AW, Bury G, Plunkett PK, Gibney D, Smith M, Mullan E, Johnson $Z$. Randomised controlled trial of general practitioner versus usual medical care in an urban accident and emergency department: process, outcome, and comparative cost. BMJ 1996;312:1135-42.

10 Ward P, Huddy J, Hargreaves S, Touquet R, Hurley J, Fothergill J. Primary care in London: an evaluation of general practitioners working in an inner city accident and emergency department. J Accid Emerg Med 1996;13:1115.

11 Dale J, Lang H, Roberts JA. The cost effectiveness of treating primary care patients in Accident and Emergency: a comparison between general practitioners, senior house comparison between general practitioners, se
officers and registrars. BMJ 1996;312:1340-4.

12 MacKoul D, Savageau J. Emergency department utilisation in a large paediatric group practice. Am J Med Quality 1995;10:88-92.

13 Chan LS, Galaif MA, Kushi CL, Bernstein S, Fagelson HJ, Drozd PJ. Referrals from hospital emergency departments to primary care centers for non-urgent care. Journal of Ambulatory Care Management 1985:57-69.
14 Hansagi $\mathrm{H}$, Carlsson B, Olsson $\mathrm{M}$, Edhag O. Trial of a method of reducing inappropriate demands on a hospita emergency department. Public Health 1987;101:99-105.

15 Kuensting LL. "Triaging out" children with minor illnesses from an emergency department by a triage nurse: where do they go? J Emerg Nursing 1995;21:102-8.

16 Selby JV, Fireman BH, Swain BE. Effect of co-payment on use of the emergency department in a health maintenance organisation. N Engl J Med 1996;334:635-41.

17 Middleton EL, Whitney FW. Primary care in the emergency room: a collaborative model. Nursing Connections 1993;6: room: a 29 . 40 .

18 Straus J, Orr ST, Charney E. Referrals from an emergency room to primary care practices at an urban hospital. Am J Public Health 1983;73:57-61.

19 Kelly KA. Cost containment in the emergency department: shifting the cost of caring for patients with non-emergency conditions from crowded emergency departments to primary care settings. J Emerg Nursing 1994;20:454-7.

20 O'Shea JS, Collins EW, Pezzullo JC. An attempt to influence health care visits of frequent hospital emergency facility users. Clin Pediatr 1984;23:559-62.

21 Geyman JP. How effective is patient education? J Fam Pract $1980 ; 10: 973$.

22 Henry GL. Refusal of care: the ethical dilemma [letter]. Ann Emerg Med 1990;19:1197-200.

23 Garcia de Ancòs J, Dale J, Roberts J. An economic evaluation of the costs perceived by patients who decide to attend A\&E for primary care. Proceedings of the Annual Scientific Meeting of the AUDGP, Aberdeen, 1993.

24 Williams RM. The costs of visits to emergency departments. N Engl J Med 1996;334:642-6.

25 Dale J, Rennie D, Roberts J, Tyson L. Minor injury services: a major public concern: an option appraisal for Bromley Health. London: King's College School of Medicine and Dentistry, Department of General Practice and Primary Care, October 1994.

26 Gyldmark M. A review of cost studies of intensive care units: problems with the cost concept. Crit Care Med units: problems

27 NHS guide to evaluating clinical trials. London: Department of Health, 1994.

\section{To all referees}

The fournal of Accident and Emergency Medicine gratefully acknowledges the contribution of all reviewers:

Thomas Beattie

Kenneth Boffard

Anthony Brown

Rob Cocks

Mike Clancy

Christine Dearden

Roger Evans

Jerris Hedges
Geoffrey Hughes

Robin Illingworth

Michael Lambert

Roderick Little

Christopher Luke

Kevin Mackway-Jones

Mike McCabe

Alastair McGowan
Francis Morris

Patrick Nee

Barbara Phillips

Laurence Rocke

David Skinner

Robin Touquet

David Yates 